\title{
Scientific Understandings Revealed by Students' Computer Models of a Stream: A Trickle or a Flood?
}

\author{
Valerie L. Talsma \\ School of Education - University of Pittsburgh, 4C10 WWP Hall, Pittsburgh, PA 15260 \\ PH: 412-648-7313, Fax: 421-648-3131 \\ email: vtalsma@pitt.edu
}

\begin{abstract}
Analysis of student constructed computer models is important in order to determine their overall educational value, identify general misconceptions or gaps in both conceptual and epistemological understandings at the classroom level, and assess students' individual achievement levels. This study examines a set of such models constructed during a high school investigation of a local creek. Affordances for the demonstration of conceptual, epistemological and strategic understandings were identified before searching for these understandings in the models. The computer models as a set represent a substantial portion (70\%) of the scientific content in the creek project. Ecological content was most strongly represented in the models and most students were able to model causal linkages between biology, earth science, physical science and/or environmental science phenomena. The models potentially represent a much smaller proportion of the epistemological and strategic content of the project. However, these understandings were more tightly scaffolded by the task, so most of the models showed evidence of these types of understandings. Analysis of the content in the models provides evidence of the veracity of students' understandings. Students demonstrated more understandings around specific content than they did about the strategic or epistemological understandings of modeling.
\end{abstract}

Keywords: modeling/models; assessment; high school; science education,

The educational literature suggests that with the support of active teaching strategies, students involved in sustained inquiry about a real problem situated in their world develop robust understandings. In this study, I explore the scientific understandings students developed about ecosystems as represented in their construction of dynamic computer models of a stream ecosystem.

Scientific understanding is demonstrated when an individual "integrates a complex structure of many types of knowledge, including the ideas of science, relationships between ideas, reasons for these relationships, ways to use the ideas to explain and predict other natural phenomena, and ways to apply them to many events (NRC, 1996)." This study is also informed by those authors who have described different dimensions or frames of understandings (e.g. Schwab 1964; Posner, Strike et al. 1982; Schoenfeld 1985; Perkins and Simmons 1988; Brown, Collins et al. 1989; Perkins 1991; White and Gunstone 1992; Perkins, Crismond et al. 1995). For this study, I use three dimensions of understanding. The dimension of conceptual understandings includes content knowledge, its organization and internal structures. The epistemological dimension relates to understandings of the scientific discipline, its purpose, syntax and how the canons are applied to inquiry. The strategic dimension encompasses the understandings of how to carry out investigations, conduct inquiry, solve problems and employ other strategies that relate to a functional component (Anderson \& Roth, 1989) of scientific understanding.

One context in which a learner demonstrates scientific understanding is through the process of building explanatory mechanisms of scientific phenomena (theories and models). The process of building explanations involves observing phenomena, building models to represent, explain and predict the phenomena, and revising previous models or explanations to account for new observations and evidence. An understanding of the nature of models and model building is an integral component of scientific literacy (Gilbert, 1991; NRC, 1996; AAAS, 1993). The construction of dynamic models encourages analyzing, synthesizing, reasoning and explaining (Spitulnik, et al., 1999). These processes help students develop both strategic and epistemological understandings as they create and revise their models, and conceptual understandings as they attempt to explicate relationships between the different parts of their models

Student use of models had been an area of inquiry into student scientific understandings (e.g., Smith et al., 1987; White, 1993; Brand, Pulver, \& Rader, 1997). With the advent of age-appropriate modeling tools (e.g. Cocoa, Stella, Model-It, Logo \& StarLogo), a few studies have focused on students' construction and revision of models. These studies show that when students create dynamic models (or work with model-based simulations) they come to 
understand complex phenomena as interconnected systems (Lewis, Rader, Brand, \& Carlone, 1997; Miller, et al., 1993; Spitulnik, et al., 1999; Stratford, Krajcik, \& Soloway, 1997a; Stratford, Krajcik, \& Soloway, 1997b, Resnick, 1994; Resnick, 1996), develop understandings of how scientists use models (Richards, et al., 1992) and understand and apply concepts of systems thinking to scientific problems (Mandinach, 1989)

The present study focuses on describing and characterizing the types of scientific understandings students demonstrate in their creation of dynamic computer models of a creek ecosystem.

\section{The Learning Environment}

This study focuses on a ninth grade $\left(\mathrm{n}_{\text {students }} \approx 100\right)$, fall semester science curriculum on ecology and streams in a small public high school. The stream ecology curriculum is interdisciplinary, combining content from earth science, biology and chemistry; and has been aligned with a number of National Standards (NRC, 1996) that map across the conceptual (33 standards), epistemological (12 standards) and strategic (11 standards) frames of scientific understanding.

One of the major student artifacts constructed during the creek curriculum were computer-based models of stream phenomena. These computer models were constructed using Model-It 3.0b software which provided a dynamic modeling environment designed specifically for learners (Jackson, Krajcik \& Soloway, 1999). Model-It models consist of objects ("things" in the system being modeled such as the creek, fish, people), factors (measurable attributes of objects, e.g. creek temperature and $\mathrm{pH}$, number of fish), and relationships between factors (e.g. as water temperature increases, dissolved oxygen decreases). Objects were represented visually with photo-realistic or graphical images. Factors were defined qualitatively with text (high to low) or quantitatively (pH range from 1-14). Relationships are defined with text (as temperature increases, DO decreases) or graphically.

During the creek project, student's engaged in two, week long, cycles of modeling creek phenomena. During the first model building cycle (week 11 of the project), student pairs became familiar with the Model-It software and built and tested a model of the physical and biological factors in their creek. The second modeling cycle occurred at the end of the semester project (week 18) and was assessed as the students' final exam grade. For this assessment, students were asked to build a model that demonstrated "in-depth understanding of a stream ecosystem" and that included physical, chemical, and biological factors of the stream. Most students worked in pairs at the computers during classtime and were also able to work on their models during lunch and after school.

Students demonstrated their conceptual understandings in the content of the model while epistemological and strategic understandings were represented in the planning and evaluation of the model. The modeling assignment, when mapped onto the National Science Education Standards, afforded students the opportunity to demonstrate conceptual understandings along 25 standards distributed across four content areas, four strategic understandings and four epistemological understandings.

\section{Data Collection}

Multiple sources of qualitative and quantitative data were collected, including: Field notes; audio/video recordings of classroom instruction; copies of curriculum materials, especially project handouts and teachers' academic work assignments; copies of student generated artifacts; and pre- and post-tests (constructed response essay, short answer and multiple choice questions) of student's scientific understanding.

Specifically for this study, text and electronic copies of student constructed computer models were collected. A total of 46 models $\left(n_{a}\right)$ created by 85 students $\left(n_{S}\right)$ were collected off the class server. Printouts of each model, which include students' plans, goals, descriptions of factors and objects, explanations of relationships, factor and relationship map, and the student's evaluations of their models were made. Digital data included both students' computer models and the logfiles of their work in Model-It.

\section{Analysis}

The analysis of the students' models involved careful examination of the both text and electronic version of the model to identify scientific understandings that matched one or more National Standards addressed by the curriculum and afforded by the assignment. Once a standard was identified, the students' level or degree of development of understanding was determined using a four level ordinal scale (0-3) with 3 representing the level of understanding in alignment with the standards (Table 1) (Pearson product-moment correlation coefficients for interrater reliability were.70 $\leq \mathrm{r}^{2} \leq .92$ ). The ordinal data was used to calculate frequencies of demonstrated 
understandings. Signed tests were used to examine differences in understandings between the model assignment and the other measures in the larger study.

Table 2: General levels for demonstrations of Scientific Understanding for the three dimensions: conceptual, epistemological and strategic understandings.

\begin{tabular}{|c|c|c|c|c|}
\hline $\begin{array}{c}\text { Scientific } \\
\text { Understanding }\end{array}$ & Level 3 & Level 2 & Level 1 & Level 0 \\
\hline $\begin{array}{l}\text { Conceptual } \\
\text { Understandings } \\
\text { Adapted from } \\
\text { Stratford (1996) } \\
\text { Standards: B.2.5, } \\
\text { B.3.3, C.4.1, C.4.2, } \\
\text { C.4.3, C.4.4, C.4.5, } \\
\text { C.5.1, C.5.2, C.5.4, } \\
\text { C.5.5, C.5.6, D.1.1, } \\
\text { D.2.1., D.2.2, } \\
\text { D.3.3., F.2.1., F.2.3, } \\
\text { F.3.1, F.3.3, F.5.2., } \\
\text { F.5.3., F.6.5 }\end{array}$ & $\begin{array}{l}\text { Response is } \\
\text { scientifically } \\
\text { correct and } \\
\text { contains no } \\
\text { extraneous or } \\
\text { incorrect ideas, } \\
\text { statements concur } \\
\text { with expert } \\
\text { propositions } \\
\text { (scientifically } \\
\text { accurate) }\end{array}$ & $\begin{array}{l}\text { Response is } \\
\text { essentially correct } \\
\text { but contains some } \\
\text { extraneous and/or } \\
\text { incorrect } \\
\text { information } \\
\text { (partially - } \\
\text { accurate). }\end{array}$ & $\begin{array}{l}\text { Response contains } \\
\text { significant errors or } \\
\text { fundamental } \\
\text { differences } \\
\text { between the } \\
\text { student's and } \\
\text { expert's } \\
\text { conceptions (non- } \\
\text { scientific). }\end{array}$ & $\begin{array}{l}\text { Some response } \\
\text { given but does not } \\
\text { evidence } \\
\text { understanding, } \\
\text { perhaps } \\
\text { nonsensical OR } \\
\text { Student did not } \\
\text { provide a } \\
\text { response. (no } \\
\text { evidence) }\end{array}$ \\
\hline $\begin{array}{l}\text { Epistemological } \\
\text { Understanding } \\
\text { Adapted from } \\
\text { Carey, et al (1989), } \\
\text { Grosslight, et. al, } \\
\text { (1991) and } \\
\text { Spitulnik (1998) } \\
\text { Standards: A.2.2, } \\
\text { A.2.5, G.2.2, G.2.3 }\end{array}$ & $\begin{array}{l}\text { Recognizes the } \\
\text { cyclic, cumulative } \\
\text { nature of science, } \\
\text { and identifies the } \\
\text { goal of science as } \\
\text { the construction of } \\
\text { ever-deeper } \\
\text { explanations of the } \\
\text { natural world. } \\
\text { (Knowledge } \\
\text { problematic) }\end{array}$ & $\begin{array}{l}\text { The motivation for } \\
\text { an activity is to test } \\
\text { an idea to see if it } \\
\text { is right. The goal } \\
\text { of science is } \\
\text { understanding } \\
\text { natural } \\
\text { phenomena -- how } \\
\text { things in the world } \\
\text { work, a focus on } \\
\text { reality, vs. ideas. } \\
\text { (Transitional) }\end{array}$ & $\begin{array}{l}\text { No clear distinction } \\
\text { between ideas and } \\
\text { activities. The } \\
\text { motivation for an } \\
\text { activity is the } \\
\text { achievement of the } \\
\text { activity itself, rather } \\
\text { than the } \\
\text { construction of } \\
\text { ideas. The goal of } \\
\text { science is to } \\
\text { discover facts and } \\
\text { to invent things. } \\
\text { (Knowledge } \\
\text { unproblematic) }\end{array}$ & $\begin{array}{l}\text { Some response } \\
\text { given but does not } \\
\text { evidence } \\
\text { understanding, } \\
\text { perhaps } \\
\text { nonsensical OR } \\
\text { Student did not } \\
\text { provide a } \\
\text { response. (no } \\
\text { evidence) }\end{array}$ \\
\hline $\begin{array}{l}\text { Strategic } \\
\text { Understandings } \\
\text { Adapted from } \\
\text { Spitulnik (1998). } \\
\text { Standards: E.1.1, } \\
\text { E.1.2, E.1.3, E.1.4 }\end{array}$ & $\begin{array}{l}\text { Student } \\
\text { independently } \\
\text { defines, plans, } \\
\text { implements and } \\
\text { evaluates a line of } \\
\text { inquiry or } \\
\text { representation of } \\
\text { understanding } \\
\text { (e.g. a model). }\end{array}$ & $\begin{array}{l}\text { Student defines, } \\
\text { plans, implements } \\
\text { and/or evaluates a } \\
\text { line of inquiry or } \\
\text { representation of } \\
\text { understanding with } \\
\text { help. May be } \\
\text { constrained or } \\
\text { limited by task } \\
\text { affordances }\end{array}$ & $\begin{array}{l}\text { Students has } \\
\text { difficulty defining a } \\
\text { reasonable } \\
\text { problem area given } \\
\text { constraints, } \\
\text { problem may be } \\
\text { too broad. Does } \\
\text { not go beyond } \\
\text { minimum } \\
\text { requirements of } \\
\text { the assignment }\end{array}$ & $\begin{array}{l}\text { Some response } \\
\text { given but does not } \\
\text { evidence } \\
\text { understanding, } \\
\text { perhaps } \\
\text { nonsensical OR } \\
\text { Student did not } \\
\text { provide a } \\
\text { response. (no } \\
\text { evidence) }\end{array}$ \\
\hline
\end{tabular}

Students' conceptual understandings (CU) were derived from descriptions of factors, relationships between factors and explanations for those relationships. For epistemological understandings (EU), students' models were examined to see: how students describe the purpose of their models, the extent to which they provided rationales or explanations, their evaluation, testing and/or revision of their models (determined from the model log files), and the extent to which students identified science as a human construct and thus subject to change.

Strategic understandings (SU) encompassed those understandings involved with action, doing and procedures, including asking questions, designing and building the model, organizing and incorporating data, and employing other strategies that relate to the functional component of understanding. For strategic understandings, student models were examined for: students' definition of the problem area addressed in their model, their representation of the plan or design process, their construction of explanations within the models and the models themselves, and the support of any claims with empirical evidence. 


\section{Findings}

The analysis of a relatively simple model created by an individual demonstrates how student understandings were identified and characterized in their models. This mini-case will be followed by a summary of the findings of scientific understandings represented in the class set of models.

\section{Chase's Model of the Effects of Forest Fires}

For his final model, Chase, a male student working alone, decided that he wanted to create of model "to show how a forest fire would affect various characteristics of the creek." In the planning of his model, Chase defined his purpose/ problem and he began to plan the model by filling out the fields in the planning window of the Model-It software (Figure 1). The scientific understandings demonstrated in this part of the model include:

Problem Definition (SU-E.1.1) - because Chase required some discussion with the classroom teacher about his problem (Field notes 1/8/97) and because he did not include a prediction of how he expected the fire to affect the creek (Figure 1), his understanding of this strategic standard was coded at level 2.

Purpose of the model (EU- A.2.2) - In choosing to model a forest fire, Chase was pursuing a hypothetical situation. Therefore, his model was interpreted as "developing and testing ideas (theories, possibilities)" - Level 3 understanding as opposed to a focus on reality (Level 2).

Planing the model (Objects \& Factors) (SU-E.1.2). In the third and fourth fields of the plan notepad Chase identified 3 objects and 3 factors for his model (Figure 1). These included two of the three objects and 3 of the 6 factors he actually included in his model. Thus, his understanding on this standard was coded at Level 2 - 33-66\% of objects and factors identified in plan. In the Model, Chase created three objects: stream, using a digital image from the class sever; fire modifying a ClarisWorks clip art; and sunlight - clipart. Chase did not include any rationales for any of the objects and factors in his plan (Answers to the "Why?" question in the prompt). Therefore, his demonstrated understandings for standard EU-A.2.5 was coded at Level 0 for no evidence

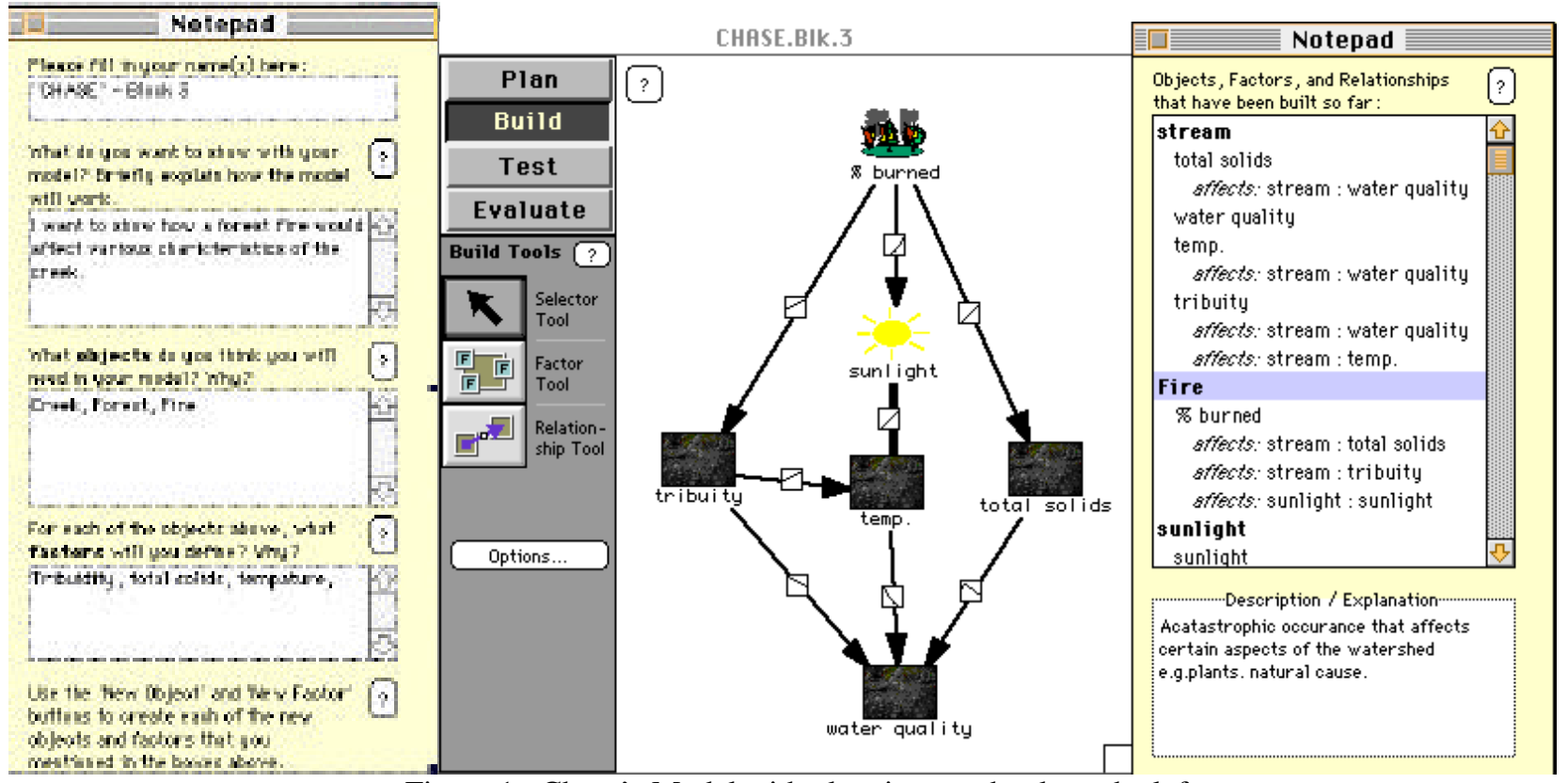

Figure 1: Chase's Model with planning notebook on the left.

Chase require a little assistance in manipulating the software during the beginning of the building phase until he regain familiarity (Field notes 1/11/97). He then proceeded to construct a model with three objects, six factors, and nine relationships (Figure 1). In the descriptions of the factors and relationships, Chase demonstrated his conceptual understanding. For example, in his creation of the factor, "stream: total solids", Chase demonstrated his conceptual understanding of this stream factor in two ways: in his description of the factor, "Total solids are the dissolved matireals and the suspended matireals" [sic] and in his definition of the range, quantitatively from 0 to 500 $\mathrm{mg} / \mathrm{L}$. Since both Chase's description and his defined range were scientifically accurate, and because his 
understanding of total solids maps onto the Standard on states of matter/ mixtures and solutions (B.2.5), Chase's conceptual understanding on this standard was coded at Level 3.

Chase also demonstrated his conceptual understandings in building the relationships between factors. For example, in the relationship between total solids and water quality, Chase demonstrated a high degree of understanding (Level 3) in three areas: he created a scientifically accurate relationship (Mitchell \& Stapp 1994, p. 84.); he provided an accurate explanation for this relationship and he provided an elaborate explanation by listing more than two causes. Chase listed four accurate effects: the reduction of water clarity due to increasing turbidity, a decrease in photosynthesis rates caused by a reduction in sunlight penetration, the possibility that these materials will bind to pollutants, and an increase of stream temperature caused by the absorption of sun energy of the total solids. The content of this relationship maps onto Standard D.3.3 - Interactions of Earth Systems. Chase's demonstrated understanding of this standard was coded at Level 3.

In the earth and space sciences, Chase's model addressed Standard D.1.1 - Sources of Energy. This understanding was demonstrated in three relationships: stream: tribuity [sic - turbidity] affects stream: temp[ature], Fire:\%burned affects sunlight:sunlight, and sunlight:sunlight affects stream:temp (Figure 1). In these three relationships, while the overall sense of the relationships is correct, there are some small errors. For example in the relationship between Fire:\%burned and sunlight:sunlight, the shape of the relationship should be "increases by a little" not by "more and more." The banks of the stream comprise only a small part of the watershed that is burned, but this is the only area that would be shading the steam and thus affecting sunlight so although a large amount of the watershed might burn, a much smaller percent of that affects the sunlight reaching the stream. Another relationship, between sunlight and temperature, lacked an explanation. For these reasons, Chase's demonstrated understandings along Standard D.1.1 were coded at Level 2.

The Model-It 3.0b environment also afforded Chase the opportunity to test his model. On day two of model construction, Chase conducted a test of the relationships emanating from the factor fire:\%burned. Chase selected relationships, opened meters, started the test, changed \%burned from 0 to $49 \%$, stopped the test and then created a new relationship between turbidity and stream temperature. Later, Chase tested this new relationship. He then created the factor stream:water quality and built the three relationships that affect it. He ran a final test of the model after which he edited the factors \%burned and water quality. Because Chase tested his model, it was possible to make a determination of his demonstrated understanding about the nature of knowledge in models (EUG.2.2). In the sequence described above, Chase tested his model and revised it to produce a desired outcome. There was no evidence that Chase was testing ideas and revised his model to better account for evidence (Level 3). Therefore his demonstrated epistemological understanding for standard G.2.2 was coded at Level 2.

In his model evaluation Chase responded to two questions. In the first, "How well does your model work, or if it doesn't, why not?" Chase replied, "It worked well I enjoyed building it and it showed me how a creek is affected by fire." This response was classified as a Level 2 understanding for strategic understanding standard E.1.4 because, although Chase did compare the model to his purpose, he did not provide any evidence for how well the model worked. In the second question, "What would you change to make your model work better or be more complex?" Chase wrote, "I would make the amount of sunlight start a little higher seeing as a real creek is not totally blocked from the sun by trees." This response was coded at Level 2 for the epistemological standard G.2.3 on the tentative nature of science because this would not involve a substantial change to the model and he does not indicate that he would use empirical values in the model (Level 3 understandings).

Chase's model included factors and content from the physical and chemical assessment of the creek. His model did not explicitly include biological factors, which were part of the assignment. Never the less, Chase's overall model showed an elegance and parsimony that explained the essential effects of a forest fire on the creek. Therefore, for strategic understanding E.1.3 - Implementing a plan/building the model, Chase's demonstrated level of understanding was coded at Level 3.

Overall, in his model, Chase demonstrated a Level 2 (partial or developing understanding on the standards) across each of the dimensions of scientific understanding. In this sense, he was similar to his classmates at the end of the creek project. The understandings demonstrated by the class set of models are explored in the next section. Most of these models were more complex than Chase's. Students created an average of 5.42 objects (range 1-12), 10.38 factors (range 5-22), and 13.82 relationships (range 5-36). The models addressed an average of 10.6 standards (range 5-16) across the conceptual, epistemological and strategic dimensions. These are examined in the next sections. 


\section{Conceptual Understandings of the Creek}

Conceptual understandings were demonstrated in the factors and relationships that students created. The largest fraction of the defined factors (32\%) was ascribed to biological organisms in the creek (e.g. population number for taxa 1, birth rate, etc.). The water quality index and its related nine parameters accounted for the second largest cluster of 29\%. All nine water quality parameters (Mitchell \& Stapp, 1994) were accounted for in different models. Thirty-six models included the factor of dissolved oxygen. Temperature was the second most frequent water quality parameter. Nitrates and total solids were the least common factors in this cluster, appearing in just seven models. The WQI (water quality index) or general stream health was a factor in 13 models.

Factors that students had studied in their physical assessment of the creek accounted for $11 \%$ of the defined factors. The most frequent physical assessment factors were discharge (15 models) and bank erosion/stability (11 models). Outside influences, such as weather, pollution and land uses/human activity, accounted for $26 \%$ of all factors.

The set of models included 631 relationships between factors. Of these, $23 \%$ involved some factor outside of the creek causing a change on a factor inside the creek and $65 \%$ involved within creek relationships. The most common was that of some creek factor (e.g. dissolved oxygen (45 cases) or $\mathrm{pH}$ (21 cases)) affecting the benthic organisms. The high number of relationships between abiotic factors of the creek and the biological organisms is also evident in the analysis of the National Standards with $87 \%$ of the models addressing standard C.5.5 (environmental limits).

The students' models addressed an average of five standards in the conceptual understandings frame (standards B, C, D \& F) per model or $~ 15 \%$ of the curriculum. However, the set of models included understandings that mapped on to 23 standards (70\% of the curriculum content and $92 \%$ of the standards afforded by the assignment). Ten models (21.7\%) addressed all four science areas and 21 (45.7\%) addressed three of the four areas. Ninety-one percent of the students demonstrated overall understandings of Level 2 or higher. The median level of conceptual understanding in the models was Level 2 with only a few models $(4.4 \%)$ indicating a more robust Level 3 understanding across the entire model. However, conceptual understandings were not demonstrated evenly across models with students demonstrating more robust understandings in some standards and weaker understandings in other standards.

All but two of the models (Chase's being one) included some biology content. This content fell into two sub-standard areas: C.4 - The interdependence of organisms such as food chains and competition and C.5 - Matter, energy \& organization in living systems. One understanding that appeared in the greatest number of models related to standard C.5.5 and includes the understanding that biological organisms have certain tolerances or limits to environmental factors. A common representation of this understanding was the notion that benthic macroinvertebrates have different sensitivities to oxygen levels. Other environmental factors that were used in models this way were temperature, $\mathrm{pH}$, turbidity, and phosphates (for algae). The other most frequent set of conceptual understanding in the life science was decomposition (C.5.1) (41\%).

\section{Strategic and Epistemological Understandings of Modeling}

Strategic and epistemological understandings were determined from the students' entries into the plans and evaluations fields in their model notebooks. Thirty-nine models (85\%) included plans and $31(67 \%)$ included model evaluations.

Many of the modelers (82.6\%) were able to define reasonable phenomena to be addressed by their models. Most of the models included plans that identified the majority of the important objects and factors and another 16 identified between one and two thirds of the object and factors. All students actually designed a model that could be manipulated but often included redundant relationships or superfluous factors that detracted from the workability of the models (Level 2). Four models (e.g. Chase's) exhibited an elegance and parsimony that rated a Level 3 code.

Most students (65\%) built models with a specific purpose focused on reality (Level 2), for example, the impact that weather phenomena, golf courses or construction would have on the creek. Only eight models focused more on ideas or the testing of possibilities or theories (Level 3). In making their plans for their models, fewer than half the students provided any rationales for including particular objects or factors. 
In the model evaluation, students were asked to comment on what they would change. Students generally responded that they would add more factors, a response that was coded as Level 2, reflecting an epistemology of science characterized by the addition of new information (Table 1). Seven models were coded at Level 3 - an epistemology that reflects the tentative nature of science with theories and models subject to change as new data becomes available.

None of the model builders used data that they had collected in the field to define model relationships although several did use the graphs in their text (Mitchell \& Stapp, 1994) to more accurately define relationships between specific parameters and water quality.

\section{Conclusions}

The computer models assigned as the summative assessment in the Traver Creek Curriculum provided the opportunity for students to demonstrate their scientific understandings across a substantial portion of the standards which the curriculum was designed to address. Twenty-five of the 33 conceptual standards were afforded by the modeling assignment and students demonstrated understandings on 23 of these as a class. Individual models tended to include just a "trickle" of the afforded content although some models demonstrated a quite respectable "flow" of understanding. All of the models demonstrated understandings that were integrated across two or more content domains (physical science, life science, earth science and environmental science). Few demonstrated understandings were coded at level one, indicating that students included content that they felt they understood. The models potentially represent a much smaller proportion of the epistemological (33\%) and strategic (36\%) content of the project. However, the notepad feature more tightly scaffolded these understandings so $89 \%$ of the students showed evidence of these types of understandings. A scientific epistemology of parsimony in explanations may also serve as a flow regulator, discouraging a flood of content in an individual model. Such interactions between the dimensions of scientific understanding warrant further investigation.

In the analysis across all the measures, students showed significant gains $(\mathrm{p}=.05-.000)$ in understandings over the course of the semester (Talsma \& Krajcik, 2000). On the post test instrument completed immediately after the modeling exercise reported here, students demonstrated the same levels of understanding along the measured standards (no significant difference in the sign-rank test at $\mathrm{p}=.05$ ).

This study used a criterion-referenced model to make the assessment of artifacts more objective. This was accomplished by explicitly mapping demonstrations of student understandings onto the National Standards with defined levels of achievement. While such methods have been used in assessments, the usefulness of using the National Science Education Standards (NRC, 1996), which tend toward broad conceptual understandings, needs to be further studied.

The construction of computer models alone will not promote scientific understanding, but rather learning environments that encourage inquiry and value the process of artifact construction, including collaborating, reviewing and revising will be more likely to encourage the construction of scientific understanding. However, artifacts can be useful in assessing scientific understandings as they are concrete representations of the functionality of such understandings.

\section{References:}

AAAS - The American Association for the Advancement of Science (1993). Benchmarks for Science Literacy. New York, Oxford University Press.

Anderson, C. W., \& Roth, K. J. (1989). Teaching for meaningful and self-regulated learning of science. Advances in Research on Teaching: A research annual. J. Brophy, (ed.), 1(1), 265-309.

Brand, C., Pulver, P., \& Rader, C. (1997). Using visual models in an elementary classroom. In A paper presented at the Annual Meeting of the National Association for Research in Science Teaching, . Oakbrook, IL:

Brown, J. S., Collins, A., \& Duguid, P. (1989). Situated Cognition and the Culture of learning. Educational Researcher, 18(1), 32-42.

Grosslight, L., Unger, C., Jay, E., \& Smith, C. L. (1991). Understanding models and their use in science: Conceptions of middle and high school students and experts. Journal of Research in Science Teaching, 28(9), 799-822.

Jackson, S. L., Krajcik, J., \& Soloway, E. (1998). The design of guided learner-adaptable scaffolding in interactive learning environments. Submitted to CHI '98. 
Lewis, C., Rader, C., Brand, C., \& Carlone, H. (1997). Models children build: Content, logic and educational impact. In A paper presented at the Annual Meeting of the National Association for Research in Science Teaching, . Oakbrook, IL:

Mandinach, E. B. (1989). "Model-building and the use of computer simulation of dynamic systems." Journal of Educational Computing Research 5(2): 221-243.

Miller, R., Ogborn, J., Briggs, J., Brough, D., Bliss, J., Boohan, R., Brosnan, T., Mellar, H., \& Sakonidis, B. (1993). Educational tools for computational modeling. Computers in Education, 21(3), 205-261.

Mitchell, M. K. and W. B. Stapp (1994). Field Manual for Water Quality Monitoring. Dexter, MI, Thomson-Shore, Inc.

NRC - The National Research Council (1996). National Science Education Standards, Washington, DC: National Academy of Sciences.

Perkins, D. N. (1991). "Educating for Insight." Educational Leadership 49(Oct): 4-8.

Perkins, D. N. and R. Simmons (1988). "Patterns of misunderstanding: an integrative model for science, math, and programming." Review of Educational Research 58(Fall): 303-326.

Perkins, D. N., Crismond, D., Simmons, R., \& Unger, C. (1995). Inside Understanding. In D. N. Perkins, J. L. Schwartz, M. M. West, \& M. S. Wiske (Eds.), Software Goes to School: Teaching for understanding with new technologies New York, NY: Oxford University Press.

Posner, G. J., Strike, K. A., Hewson, P. W., \& Gertzog, W. A. (1982). Accommodation of a scientific conception: Toward a theory of conceptual change. Science Education, 66(2), 211-227.

Resnick, M. (1994). “Changing the centralized mind.” Technology Review 97:32-40 Jul '94.

Resnick, M. (1996). New paradigms for computing, new paradigms for thinking. Constructionism in Practice: Designing, thinking and learning in a digital world. Y. Kafai and M. Resnick. Mahwah, NJ, Lawrence Erlbaum Assoc.: 255-267.

Richards, J., Barowy, W., \& Levin, D. (1992). Computer simulations in the science classroom. Journal of Science Education and Technology, 1(1), 67-79.

Schoenfeld, A. H. (1985). Mathematics, technology, and higher order thinking. Technology and education: Looking toward 2020. R. S. Nickerson and P. P. Zodhiates. Hillsdale, NJ, Erlbaum: 67-96.

Schwab, J. J. (1964). Structure of the Disciplines: Meanings and significances. The Structure of Knowledge and the Curriculum. G. W. Ford and L. Pugno. Chicago, IL, Rand McNally \& Co.: 1-30.

Smith, M. L. and G. V. Glass (1987). Research and Evaluation in Education and the Social Sciences. Boston, MA, Allyn and Bacon.

Spitulnik, M. W., S. Stratford, Krajcik, J., \& Soloway, E. (1996). Using Technology to Support Students' Artifact Construction in Science._International Handbook of Science Education. Netherlands, Kluwer Publishers.

Spitulnik, M. W. (1998). Construction of technological artifacts and teaching strategies to promote flexible scientific understanding, University of Michigan - School of Education.

Stratford, S. J., J. Krajcik, \& Soloway, E. (1997). Secondary students' dynamic modeling processes: Analyzing, reasoning about, synthesizing and testing models of stream ecosystems. A paper presented at the annual meeting of the American Educational Research Association (AERA), Chicago, IL.

Stratford, S. J., J. Krajcik, \& Soloway, E. (1997). Technological Artifacts Created by Secondary Science Students: Examining Structure, Content, and Behavior of Dynamic Models. A paper presented at the Annual Meeting of the National Association for Research in Science Teaching (NARST), Oakbrook, IL.

Talsma, V. L. , \& Krajcik, J. (2000) Students' changing understandings of stream ecology: A Trickle or a Flood? A paper presented at the annual meeting of the National Association for Research in Science Teaching (NARST), New Orleans, LA.

White, B. Y. (1993). "ThinkerTools: Causal models, conceptual change and science education." Cognition and instruction 10(1): 1-100.

White, R. and R. Gunstone (1992). Probing Understanding. London • New York • Philadelphia, The Falmer Press.

\section{Acknowledgements}

I would like to thank the students and teachers of the Traver Creek Project for their participation in this study. This research was supported in part by the Spencer Foundation and the National Science Foundation through the Center for Highly Interactive Computing in Education (hice). 